\title{
Carbon Sequestration and Permit Trading on the Competitive Fringe
}

\begin{abstract}
$\underline{\text { Abstract }}$
This paper makes two contributions to the carbon-sequestration policy literature. First and foremost, we develop a theoretical framework in which sequestration and permittrading markets are analyzed jointly in the context of a competitive fringe model. Our framework formalizes the linkage between regulatory policy changes (as they manifest themselves in the permit market) and subsequent equilibrium allocations in the sequestration market. Second, we perform a numerical analysis demonstrating the role market structure, or market power, might play in the determination of the equilibrium sequestration allocation and carbon price. Both our analytical and numerical results demonstrate the importance of incorporating into empirical supply-side models demandside information that is reflective of an underlying market structure.
\end{abstract}




\section{Introduction}

The main focus of carbon sequestration research has thus far been the empirical estimation of supply functions, both for specific countries and globally. ${ }^{1}$ Although the supply estimates themselves vary, the general opinion emerging from this literature is that scope exists for cost-effective policies fostering both the curtailment of deforestation and promotion of reforestation in support of carbon sequestration at national, regional, and international levels. ${ }^{2}$ What has not yet been considered in this analysis, however, is the role that market structure, or market power, might play in the determination of an equilibrium sequestration allocation. This paper is a first attempt at characterizing the role of market structure in the context of a carbon sequestration model that also incorporates an existing permit-trading market, and is thus in keeping with the multiinstrument policies promulgated in recent international climate-change agreements spurred by the Kyoto Protocol (UNFCCC, 1998).

A similar issue was faced roughly 20 years ago with respect to permit trading, when Hahn's (1984) seminal article demonstrated the importance of market power in determining an equilibrium outcome. Hahn's principle result was that if a single firm with market power purchases(sells) permits in an otherwise competitive market it will behave as a monopsonist(monopolist). Thus, the degree of market inefficiency is systematically related to the initial distribution of the permits. Since then, permit-trading research has attempted to quantify the extent to which monopoly and monopsony power

\footnotetext{
${ }^{1}$ With respect to country-specific studies, see Stavins (1999) and Lubowski, et al. (2006) for the US, Xu (1995) for China, Fearnside (1995) for Brazil, Ravindranath and Somashekhar (1995) for India, de Jong, et al. (2000) for Mexico, and Sedjo (1999) for Argentina. See Benitez, et al. (2007) and Sohngen and Sedjo (2004) for estimates of global supply.

${ }^{2}$ Reforestation is not the only form that carbon sequestration can conceivably take. Alternatives include agricultural sequestration in soils and geological sequestration in mature oil fields, coal beds, or deep saline aquifers (Lal, 2004; U.S.DOE, 2009).
} 
influence the trading equilibrium, most notably in the field of experimental economics using auction-type environments. ${ }^{3}$ Contrary to these earlier works, which assume the existence of monopoly and monopsony power, we develop a competitive fringe model of carbon sequestration in the presence of permit trading. The presumption of a competitive fringe is premised on two strands of the sequestration literature - the first strand is empirical, the second theoretical.

With respect to the empirical literature, Benitez, et al. (2007) estimate global sequestration supply curves for afforestation and reforestation activities based on highly disaggregated (grid-level) physical data with country-level controls for political, financial, and economic risks. They find that low-cost sequestration sites are mainly located in regions of the developing world, such as Sub-Saharan Africa, southeastern Brazil, and Southeast Asia. ${ }^{4}$ This suggests inter alia that national-level findings, most notably those of Stavins (1999) and Lubowski, et al. (2006), must be tempered by the fact that domestic sequestration policies are likely to co-exist, be supplemented by, or be preempted by international or regional agreements to combat climate change. As a result of global comparative advantages, such as those identified by Benitez, et al. (2007), the equilibrium that emerges in a regional or global sequestration market may be governed more by the interplay of a dominant firm (or nation or region) and a competitive fringe than by perfect competition within a given nation.

\footnotetext{
${ }^{3}$ See Muller, et al. (2002) and Godby (2000) for examples of this strand of the experimental literature.

${ }^{4}$ Sohngen and Sedjo's (2004) numerical analysis of global sequestration potential is not as sanguine about the extent of these regional comparative advantages. Nevertheless, recent sequestration projects sponsored by the United Nations and World Bank involving both governmental agencies and non-governmental organizations (including cooperatives consisting of individual landholders) in Sub-Saharan and East Africa, Central and Latin America, and Southeast Asia suggest the potential for the developing world's comparative advantage in sequestration, especially when the indirect benefits of poverty alleviation are accounted for (Jindal, et al., 2008; UNFAO, 2004; Jindal, et al., 2011).
} 
It is of course possible that a global market for sequestration would resemble more an oligopoly than a competitive fringe; a possibility that might increase as alternative forms of sequestration (e.g., soil and geological as discussed in Lal (2004) and U.S.DOE (2009)) are legitimized through future international policy. However, as Asheim, et al. (2006) point out, there are fairly general conditions under which multiple regional agreements (that internalize global externalities such as climate change) outperform a single global agreement. In particular, the authors find that a regime with two agreements can Pareto dominate a regime based on a single global treaty, implying that regional cooperation might be a good alternative - or supplement - to a global environmental agreement. In a world governed by such regional agreements, oligopolies may be less likely to form. Instead, regional sequestration agreements may feature dominant countries with relatively large sequestration supplies interacting with competitive fringes of countries with relatively small supplies.

Consider, for example, a regional agreement between the US and Brazil. Brazil, for its part, could potentially act as a dominant firm due to its relatively low marginal costs of sequestration (associated with existing reforestation opportunities on vast tracts of public land (Benitez, et al., 2007)). US farmers would in turn act as a competitive fringe due to their relatively high marginal costs of sequestration (associated with existing opportunity costs for alternative private land uses (Lubowski, et al., 2006)). In turn, international trading in sequestered carbon might complement an existing domestic permit-trading market in the US that includes the nation's largest industrial polluters.

Acknowledging the fact that different market structures may in fact arise as sequestration gains greater international recognition as a tradable carbon sink, we develop 
in this paper a theory of a competitive sequestration fringe in conjunction with an existing permit trading market (for abatement by polluters). We then demonstrate through numerical analysis the responsiveness of equilibrium sequestration to changes in the relative cost structures of the dominant firm and competitive fringe, as well to stricter regulatory policy in the permit market. With respect to the latter case, we find that increases in polluting firms' required abatement levels induce higher sequestration levels from the dominant firm and the competitive fringe, as well as from the low-cost polluter. The equilibrium carbon price rises in tandem with these changes.

We begin our analysis in Section 2 with a graphical exposition of the competitive fringe model in the presence of permit trading. Section 3 develops a mathematical framework and numerical model, which is then solved for an initial set of parameter values and for subsequent changes in the relative cost structures embodied by these parameters, as well as for changes in regulatory standards. The results of the numerical analysis are discussed in Section 4. Section 5 concludes.

\section{Graphical Analysis of the Joint Competitive Fringe - Permit Trading Model}

This section presents a simple graphical analysis of sequestration and permit trading in the context of a competitive fringe model. As a point of departure, consider the standard textbook model of the competitive fringe depicted in Figure 1. ${ }^{5}$

\section{[INSERT FIGURE 1 HERE]}

In this figure, residual demand for the dominant firm's output, $D^{r}$, is the horizontal difference between market demand, $D$, and the aggregate supply of the (competitive) fringe firms, $S^{f}=M C^{f}$ (the kink in $D^{r}$ occurs precisely at the vertical intercept of $S^{f}$ ). The

\footnotetext{
${ }^{5}$ This particular model is adopted from Carlton and Perloff (2004).
} 
dominant firm maximizes profit at point $d$, by setting a price of $p^{*}$ and selling $q_{d}^{*}$ units

(where $M R^{r}$ intersects $M C^{r}$ ). The competitive fringe therefore produces $q_{f}^{*}$ at point $f$ and market equilibrium occurs at point $e$, with price $p^{*}$ and total quantity $Q^{*}=q_{f}^{*}+q_{d}^{*}$.

Incorporating permit trading into this model (for ease of exposition only two polluters cum traders are needed) adds corresponding kinks to the dominant firm's residual demand curve. This expanded model is depicted in Figure $2{ }^{6}$

\section{[INSERT FIGURE 2 HERE]}

In Figure 2, the $D^{r}$ curve has kinks at prices $p_{f}$ (the vertical intercept of the competitive fringe's aggregate supply curve $S^{f}$ ) and $p_{1}$ (the vertical intercept of polluter $p l$ 's permit supply curve $S^{p l}$ ). Here, the dominant firm maximizes profit at point $e$ by setting a price of $p^{*}$ and selling $q_{d}^{*}$ units of sequestered carbon. The competitive fringe therefore produces $q_{f}^{*}$ of sequestration at point $d$ and polluter $p 1$ offers $q_{p 1}^{*}$ abatement credits for sale at point $f$ (via abatement beyond its statutorily required amount). Because the equilibrium price $p^{*}$ lies beneath the vertical intercept of its permit supply curve, polluter $p 2$ chooses not to supply a positive amount of abatement credits to the market. ${ }^{7}$ Market equilibrium occurs at point $g$, with price $p^{*}$ and total quantity sequestered $Q^{*}=q_{p 1}^{*}+q_{f}^{*}+q_{d}^{*}$

\footnotetext{
${ }^{6}$ Restricting attention to the bilateral trading behavior of any given two polluters follows the standard graphical approach (e.g., Tietenberg, 2006 and Kolstad, 2011), which illustrates the essential features of a competitive pollution market. The mathematical model presented in Section 4 formally accounts for $n$ polluters.

${ }^{7}$ Note that the vertical intercept of $D^{r}$ occurs at price $p_{2}$, which in turn is the vertical intercept of polluter $p 2$ 's permit supply curve $S^{p 2}$. The coincidence of these two vertical intercepts is consistent with the fact that for carbon prices above $p_{2}$ polluter $p 2$ also becomes a net supplier of abatement credits. With both polluters $p 1$ and $p 2$ now being net suppliers, market demand for sequestration is effectively negative, i.e., for prices above $p_{2}$ the $D^{r}$ curve extends into the second quadrant of the Cartesian coordinate system.
} 
Figure 2 brings to light a complication in the sequestration/permit trading model that is absent from the basic model depicted in Figure 1. In Figure 1, closure (via equating market demand and supply) is not really an issue. This is because the demand and supply sides of the market are separate, i.e., those demanding the good are not also supplying it, and vice versa. This is not the case in the sequestration/permit-trading model.

Recall from Figure 2 that polluter $p 1$ is a net supplier of abatement credits, and both the competitive fringe and dominant firm are also suppliers of credits (in the form of sequestration). ${ }^{8}$ Because it is explicitly included in the model, polluter $p 2$ must therefore consume the total amount of credits produced for sale, $Q^{*}$. This explains the positioning of polluter $p 2$ 's permit supply curve. The equilibrium price $p^{*}$ is consistent with polluter p2 effectively supplying a negative amount of abatement credits for sale (i.e., demanding a positive number of credits). In specific, polluter $p 2$ 's demand for credits must equal the total amount of credits offered for sale by the dominant firm, the competitive fringe, and polluter $p 1$, i.e., $Q^{*}$.

We now turn to theoretical and numerical analyses based on a full accounting of the model's components. In particular, we explicitly close the model with a market-clearing condition that is premised on statutorily required abatement levels for each polluter.

\section{Theoretical and Numerical Models}

As indicated in Section 2, the competitive fringe model of carbon sequestration and permit trading has three different types of agents/industries: (i) a dominant firm, (ii) a permit-trading market comprised of polluting firms, and (iii) a competitive fringe. We begin this section with a general analytical treatment of sequestration and permit trading,

\footnotetext{
${ }^{8}$ We henceforth use the terms "credits" and "sequestration" synonymously.
} 
which then guides the development of a numerical model to assess the responsiveness of sequestration to changes in the relative cost structures of the dominant firm and competitive fringe, as well as to changes in regulatory standards.

Heuristically, we can think of the three types of agents as participating in a two-stage game that converges to a long-run, subgame-perfect equilibrium. In the first stage, the dominant firm chooses its sequestration level based on its conjecture of the aggregate sequestration demand function, which in a deterministic setting is consistent with the assumption of perfect foresight. As stated in Section 2, this demand is "residual" in the sense that the dominant firm incorporates the competitive fringe's sequestration supply, as well as any net supply from the polluters themselves, in its determination of how much sequestration to produce (and, effectively, of which carbon price to set).

In the second stage, the polluting firms and competitive fringe take the carbon price as given and choose their respective abatement and sequestration levels. ${ }^{9}$ In conjunction with their statutorily required levels of abatement, the polluting firms' actual abatement levels determine their respective abatement-credit (or sequestration) demands (which could be negative for some firms, in which case the firms are net sequestration suppliers). A subgame perfect equilibrium is obtained in the long-run when three conditions are met: (i) the dominant firm's conjectures are realized, (ii) the dominant firm's and competitive fringe's aggregate sequestration (along with any net sequestration supplied by the polluters themselves) equates with sequestration demand, and (iii) the fringe firms each obtain zero profit (and thus the fringe in aggregate obtains zero profit).

\footnotetext{
${ }^{9} \mathrm{We}$ assume price-taking polluters in order to retain a focus on the effects of a competitive fringe in the sequestration market. Imperfectly competitive permit trading is the focus of a growing literature. See Hahn (1984) and Liski and Montero (2006) for examples. In Section 4 we simplify the model by including only two polluters, and without loss of generality assume that these two polluters behave competitively.
} 
Since a subgame perfect equilibrium is solved via backward induction, we begin by characterizing the polluting firms' and competitive fringe's respective second-stage problems. ${ }^{10}$ Polluter $i$, who participates in a competitive permit-trading market, chooses its quantity of abatement, $\widetilde{q}_{p i}$, to solve the following cost-minimization problem,

$$
\operatorname{Min}_{q \beta i} c_{p i}\left(q_{p i}\right)-p\left(q_{p i}-\bar{q}_{p i}\right), i=1, \ldots ., I
$$

where $c_{p i}$ is polluter $i$ 's total abatement cost (assumed positive and convex in $\widetilde{q}_{p i}$ ), $\bar{q}_{p i}$ is polluter $i$ 's statutorily required level of abatement $\left(\bar{q}_{p}=\sum_{i} \bar{q}_{p i}\right)$, and $p$ is the per-unit carbon price, which polluter $i$ takes as given, $i=1, \ldots . . .{ }^{11}$

The Kuhn-Tucker optimality conditions for this problem are, ${ }^{12}$

$$
c_{p i}^{\prime} \leq p, i=1, \ldots . I
$$

which result in the polluters' implicit abatement functions,

$$
q_{p l}^{*}=q_{p i}(p) \geq 0, i=1, \ldots, I
$$

which in turn define the corresponding permit demand functions,

$$
q_{p i}^{*}=q_{p i}\left(p, \bar{q}_{p i}\right)=\bar{q}_{p i}-q_{p i}^{*}, i=1, \ldots, I .
$$

\footnotetext{
${ }^{10}$ Although the sequential nature of solving for a subgame-perfect equilibrium is dynamic in the sense of agents moving from one stage in the decision-making process to the next, the model we present is static in terms of generating time paths for the quantity and price variables. While a dynamic framework, e.g., expected net-present value maximization in the presence of laws of motion for the price and regulatory variables, would add to the model's realism, it would also detract from the main focus of the analysis, which is to provide a simple framework within which to assess the interactions between sequestration and permit markets. We therefore leave construction of a dynamic version of this model to future research.

${ }^{11}$ Variables preceding the parentheses are functions of the variables and parameters included within the parentheses. Note that this problem can equivalently be expressed in terms of the polluting firm's choice of emissions rather than its abatement level. We have chosen the latter merely for expositional convenience. Also for convenience, we assume that verifying the transferability of the polluters' abatement is costless due to pre-existing monitoring by the regulatory authorities.

${ }^{12} c_{p i}^{\prime}$ represents the first partial derivative of function $c$ with respect to $\widetilde{q}_{p i}$.
} 
Polluters with $q_{p i}^{*}>0\left(q_{p i}^{*}<0\right)$ are permit demanders (suppliers). Curvature

conditions on $c_{p i}$ ensure that the polluting firms' problems are concave, which in turn ensure standard comparative static results, i.e., non-upward(-downward) sloping permit demand(supply) functions. For future reference, let $\phi_{p}^{*}=\sum_{i} q_{p l}^{*}$ refer to aggregate

abatement by the polluting firms and $q_{p}^{*}=\sum_{i} q_{p i}^{*}$ refer to aggregate net permit demand.

With respect to the competitive fringe, representative firm $j$ chooses its quantity of carbon sequestration, $q_{f j}$, to solve the profit-maximization problem,

$$
\operatorname{Max}_{q_{f j}} \pi_{f j}=p q_{f j}-c_{f}\left(q_{f j} ; \theta_{f j}\right)-F_{f j}, j=1, \ldots, J
$$

where $c_{f}$ is firm $j$ 's sequestration total cost (assumed positive and convex in $q_{f j}$ ), and $F_{f j}$ is a one-time, quasi-fixed licensing fee verifying the transferability of firm $j$ 's sequestered carbon $\left(F_{f}=\sum_{j} F_{f j}\right) \cdot{ }^{13}$ Explicit cost parameters $\theta_{f j}$ are included to account for structural cost changes that are assessed through numerical analysis in Section $4 .{ }^{14}$ In specific, we assume $c_{f}^{\prime}$ (i.e., the fringe firm's marginal cost) increases in $\theta_{f j}$, and, similar to polluter $i$, fringe firm $j$ takes $p$ as given in its problem. Thus, an increase in parameter $\theta_{f j}$ reflects a structural change in fringe firm $j$ 's costs such that $c_{f}^{\prime}$ increases for all $q_{f j}$.

The Kuhn-Tucker optimality conditions for this problem are,

$$
c_{f}^{\prime} \geq p, j=1, \ldots, J
$$

which result in the fringe firms' sequestration supply functions,

\footnotetext{
${ }^{13} \mathrm{We}$ acknowledge that verification of sequestration is itself an important issue, which is addressed in the environmental- monitoring and climate-policy literatures (Ney, et al., 2005; Subak, 2002). Exploring this issue here is beyond the scope of this study.

${ }^{14}$ Similar parameters could also be included in the polluters' cost functions described above. However, for the ensuing analysis we focus on the effects that this type of parameter has on the competitive fringe and the dominant firm.
} 


$$
q_{f j}^{*}=q_{f j}\left(p ; \theta_{f j}\right) \geq 0, j=1, \ldots . J .
$$

For future reference, let $q_{f}^{*}=\sum_{j} q_{f j}^{*}$. Since we assume identical firms comprise the competitive fringe, an aggregate fringe supply function may be written as,

$$
q_{f}^{*}=q_{f}\left(p ; \theta_{f}\right) \geq 0
$$

where $\theta_{f}=\theta_{1=\cdots=} \theta_{J}{ }^{15}$

Curvature conditions on $\mathrm{c}_{f}$ ensure that the fringe firm's problem is concave, which in turn ensures the standard comparative static result of a non-downward sloping aggregate sequestration supply function. Also, for future reference, note that $\frac{\partial q_{f}^{*}}{\partial \theta_{f}}<0$ at an interior solution via total differentiation of the fringe firm's Kuhn-Tucker condition and application of the curvature conditions on $c_{f}$ with respect to both $q_{f}$ and $\theta_{f}$ (the individual firm's optimality condition is identical to the industry's given the identical-firm assumption). In cases where the direct effect of $\theta_{f}$ on $c_{f}^{\prime}$ outweighs its indirect effect (via $\left.\frac{\partial q_{f}^{*}}{\partial \theta_{f}}\right)$, the fringe firm's Kuhn-Tucker condition also implies $\frac{\partial p}{\partial \theta_{f}}>0$ in equilibrium, i.e., the equilibrium carbon price rises with a positive (i.e., upward) shift in the competitive fringe's marginal cost curve.

Further, an aggregate zero-profit condition for the competitive fringe may be expressed as,

$$
\pi_{f}^{*}=p^{*} q_{f}^{*}-c_{f}\left(q_{f}^{*} ; \theta_{f}\right)-F_{f}^{*}=0
$$

\footnotetext{
${ }^{15} \mathrm{We}$ model the competitive fringe at the industry level in order to be consistent with the standard graphical analysis presented in Section 2, and thus to retain a focus on the relative market shares of the fringe as a whole and the dominant firm, rather than on sequestration per firm within the fringe. Modeling the competitive fringe in this way of course precludes us from explicitly addressing issues of entry and exit. These issues are instead considered implicitly.
} 
where $p^{*}$ denotes the equilibrium carbon price and $F_{f}^{*}$ is an implicit measure of the number of fringe firms in the industry (determined endogenously). Since it is uniquely determined by equation (3), a larger $F_{f}^{*}$ implies that a larger aggregate licensing fee is incurred by the competitive fringe in equilibrium when $F_{f j}$ remains constant for all $j$, which in turn implies a larger number of firms now existing in the industry. ${ }^{16}$

In the first stage, the dominant firm chooses its quantity of carbon sequestration, $q_{d}$, to solve the long-run profit-maximization problem,

$$
\operatorname{Max}_{q_{d}} \pi_{d}=p\left(q_{d}\right) q_{d}-c_{d}\left(q_{d} ; \theta_{d}\right)-F_{d}
$$

where $c_{d}$ is the dominant firm's total sequestration cost (assumed positive and convex in $\left.q_{d}\right)$ and $\theta_{d}$ is its associated cost parameter. As with the competitive fringe's marginal sequestration cost, we assume the dominant firm's marginal cost, $c^{Z}{ }_{d}$, is positive in $\theta_{d}$. Also, similar to $F_{f}$ for the competitive fringe, $F_{d}$ is an endogenously determined, quasifixed, one-time licensing fee verifying the transferability of the dominant firm's sequestered carbon. ${ }^{17}$

For simplicity, we assume the dominant firm's licensing fee is proportional to the competitive fringe's, e.g., as a pre-determined percentage, $v>0$, of $F_{f}^{*} .{ }^{18}$ Thus,

$$
F_{d}^{*}=v F_{f}^{*}
$$

We make particular mention of the fact that in this problem $p$ is a function of $q_{d}$. In particular, $p\left(q_{d}\right)$ is the inverse of $q_{p}^{*}$ minus the inverse of $q_{f}^{*}$; i.e., in graphical terms the

\footnotetext{
${ }^{16}$ The need to solve for an explicit number of fringe firms is obviated by the model's identical-firm assumption. Rather, the aggregate supply of sequestration is a sufficient characterization of the fringe at the level of abstraction assumed in this model.

${ }^{17}$ Assuming $p$ is negative in $q_{d}$, and given the curvature conditions on $c_{d}$ with respect to $q_{d}$, the dominant firm's problem is concave.

${ }^{18}$ We could of course assume completely separate licensing fee determination processes for the fringe and dominant firm. However, this would unnecessarily complicate the ensuing numerical analysis.
} 
dominant firm recognizes that it faces residual demand curve $D^{r}$ in Figure 2. In analytical terms, this recognition on the part of the dominant firm compels a subgame-perfect equilibrium.

The dominant firm's Kuhn-Tucker optimality condition is,

$$
p^{\prime} q_{d}+p \leq c_{d}^{\prime}
$$

resulting in the equilibrium amount of sequestration produced by the dominant firm

$$
q_{d}^{*}=q_{d}\left(\overline{\boldsymbol{q}}_{p i}, \theta_{d}\right) \geq 0
$$

where $\overline{\boldsymbol{q}}_{p i}$ is vector $\left(\bar{q}_{p l}, \ldots, \bar{q}_{p I}\right)$.

We note from equation (1) that a ceteris paribus increase in $\bar{q}_{p i}$ increases polluter $i$ 's demand for sequestration. This effectively causes the dominant firm's restricted demand curve to shift outward, in turn causing a ceteris paribus non-decreasing amount of sequestration produced by the dominant firm. Also, given the curvature conditions mentioned above, total differentiation of the dominant firm's Kuhn-Tucker condition (at an interior solution) results in $\frac{\partial q_{d}^{*}}{\partial \theta_{d}}<0$. Given a downward-sloping (residual) market demand curve facing the dominant firm, this in turn implies $\frac{\partial p^{*}}{\partial \theta_{d}}>0$.

Finally, an equilibrium clearing condition closes the model.

$$
\bar{q}_{p} \leq q_{f}^{*}+q_{d}^{*}+q_{P}
$$

Equation (6) states that aggregate sequestration from the dominant firm and the competitive fringe, $q_{d}^{*}+q_{f}^{*}$, plus aggregate abatement from the polluting firms, $q_{P}^{*}$, must be no less than aggregate statutorily required abatement, $\bar{q}_{p}$. Note that this equation also serves as a de facto market equilibrium condition, since it can be reduced to $q_{p}^{*} \leq q_{f}^{*}+q_{d}^{*}$, 
which states that net sequestration demand from the polluting firms cannot exceed the aggregate amount of sequestration produced by the dominant firm and the competitive fringe.

Equations (1) - (6) form a system of I +5 equations that can be used to solve for the I +5 equilibrium variables $\left(p^{*}, q_{d}^{*}, q_{f}^{*}, q_{p i}^{*}, F_{f}^{*}, F_{d}^{*}\right), i=1, \ldots ., I$. In addition, a corresponding equilibrium profit level for the dominant firm, $\pi_{d}^{*} \geq 0$, can be calculated.

For the numerical analysis of this model we assume, as in Section 2, the existence of two polluters, $p 1$ and $p 2 .{ }^{19}$ Total sequestration costs for the dominant firm and the competitive fringe, as well as total abatement costs for the polluters, are each

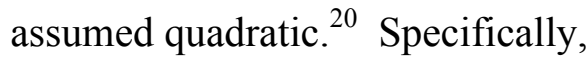

$$
\begin{aligned}
& c_{d}=\alpha_{d} q_{d}+\frac{q_{d}^{2}}{\varepsilon_{d}^{2}}+F_{d} \\
& c_{f}=\alpha_{f} q_{f}+\frac{q_{f}^{2}}{\varepsilon_{f}^{2}}+F_{f} \\
& c_{p i}=\alpha_{p i} q_{p i}+\left(\beta_{p i} q \phi_{p i}\right)^{2}, i=1,2 .
\end{aligned}
$$

where cost parameters $\alpha_{d}, \alpha_{f}, \alpha_{p i}$, and $\beta_{p i}$ and output elasticities $\varepsilon_{d}$ and $\varepsilon_{f}$ are each greater than zero, $i=1,2$ (the remaining variables were previously defined above). ${ }^{21}$ It is important to note that $\alpha_{p i}$ in (7c) is not the vertical intercept of polluter $i$ 's net sequestration supply curve, i.e., it is not equal to $p_{i}\left(\right.$ from $\left.M C^{p i}=S^{p i}, i=1,2\right)$ in Figure 2.

\footnotetext{
${ }^{19}$ The numerical simulations are performed using GAMS version 2.0.13. The input coding and output from these simulations are available from the editor of this journal.

${ }^{20}$ These functional forms are consistent with both Lubowski, et al. (2006) and Benitez, et al. (2007). Lubowski, et al. (2006) estimate a logistic aggregate supply (marginal cost) function, to which the linear marginal cost function of the quadratic specification provides a fairly close approximation. Our linear marginal cost function also approximates quite closely the quadratic function estimated in Benitez, et al. (2007) over the majority of the range of carbon sequestration considered in that study.

${ }^{21}$ In relation to the theoretical model presented above, $\alpha_{d}$ and $\varepsilon_{d}$ are subsumed in $\theta_{d}$ and $\alpha_{f}$ and $\varepsilon_{f}$ are subsumed in $\theta_{f}$.
} 
The vertical intercept is instead $\alpha_{p i}+2 \beta_{p i} \bar{q}_{p i}$, which is the first partial derivative of $c_{p i}$ evaluated at $\phi_{p i}=\bar{q}_{p i}$, i.e., where $q_{p i}$ equals zero, $i=1,2$.

Initial values for each parameter in the model are presented in Table 1. Note that these values distinguish polluter $p 2$ as being high-cost (in terms of marginal abatement cost) relative to polluter $p 1$. Polluter $p 2$ is also high-cost relative to the dominant firm and the competitive fringe. However, the slope of polluter $p l$ 's marginal cost curve $\left(2 \beta_{p l}=\right.$ 0.5 ) is less than the corresponding slope of the competitive fringe's aggregate marginal $\operatorname{cost}\left(2 / \varepsilon_{f}^{2}=2\right)$, while its vertical intercept $\left(\alpha_{p l}=0.015\right)$ is slightly larger $\left(\alpha_{f}=0.01\right)$. As in Figure 2, both the competitive fringe and polluter $p 1$ are high-cost relative to the dominant firm. These relative costs reflect the underlying assumptions of the competitive fringe model, in particular that the dominant firm generally faces lower sequestration costs than the competitive fringe and the polluters, and the competitive fringe in turn faces lower cost than at least some of the polluters. ${ }^{22}$

\section{[INSERT TABLE 1 HERE]}

Since the demand curve facing the dominant firm has a total of three kink points (one each corresponding to the vertical intercepts of the marginal sequestration/abatementcredit cost curves for the competitive fringe, $\alpha_{f}$, and the two polluters, $\alpha_{p i}+20 \beta_{p i}, i=1,2$ ) we run three separate constrained versions of the model: (i) $p^{*} \leq \alpha_{f}$, (ii) $\alpha_{f}<p^{*} \leq \alpha_{p 1}+$ $20 \beta_{p 1}$, and (iii) $\alpha_{p 1}+20 \beta_{p 1}<p^{*}<\alpha_{p 2}+20 \beta_{p 2}$ (reference the residual demand curve $D^{r}$ in Figure 2). The version of the model associated with the highest profit for the dominant

\footnotetext{
${ }^{22}$ In order to focus attention on the role of divergent abatement cost structures, we also assume equivalent required abatement levels for the polluters, i.e., $\bar{q}_{p 1}=\bar{q}_{p 2}=10$. With respect to divergence in the cost structures, we emphasize that it is not the specific parameter values that matter for the numerical analysis, rather the relative costs that are reflected in these values.
} 
firm then represents the equilibrium solution. For this particular numerical analysis model version (iii) is associated with the dominant firm's highest profit level. This is the region of residual demand where the carbon price is least restricted on the upside.

The first two cases under consideration assess the responsiveness of sequestration to changes in the relative cost structures of the dominant firm and competitive fringe. In Case 1 we introduce a step decrease (up to 10 separate steps) in the output elasticity parameter of the competitive fringe, $\varepsilon_{f}$. The step decrease, $\mu$, is a constant -0.11 . Thus, in the first step $\varepsilon_{f}$ decreases from one to 0.89 , in the second step from 0.89 to 0.78 , etc. These steps lead to progressively greater separation in costs between the competitive fringe, on the one hand, and both the dominant firm and polluters on the other. In particular, the competitive fringe becomes progressively more high-cost relative to the dominant firm and the polluters (in terms of the rates of change in marginal sequestration costs).

Alternatively, in Case 2 we introduce a constant step increase of $\mu=0.11$ (again, up to 10 separate steps) in the output elasticity parameter of the dominant firm, $\varepsilon_{d}$. Thus, in the first step $\varepsilon_{d}$ increases from 1.2 to 1.31 , in the second step from 1.31 to 1.42 , etc. As a result, the dominant firm becomes progressively more low-cost relative to the competitive fringe and the polluters.

Finally, in Case 3 we introduce constant step increases of $\mu=0.11$ in the statutorily required abatement levels of both polluters, $\bar{q}_{p i}, i=1,2$. Thus, in the first step $\bar{q}_{p i}$ increases from 10 to 10.11 , in the second step from 10.11 to 10.22 , etc., $i=1,2$. As a result, both polluters face progressively stiffer regulatory standards. 


\section{Numerical Results}

Table 2 presents our numerical results based on the initial parameter values contained in

Table 1. The second column in the table presents the benchmark equilibrium for the case of perfect competition, where the dominant firm does not exist and the sequestration market is therefore supplied solely by the competitive fringe (and any abatement credits contributed by the two polluters). ${ }^{23}$ The table's third column presents results for the competitive fringe model (i.e., with the dominant firm included).

\section{[INSERT TABLE 2 HERE]}

We begin by noting that at these initial parameter values the competitive fringe produces slightly less sequestration in aggregate than the dominant firm, i.e., $q_{d}^{*}=3.441>q_{f}^{*}=3.014$. At the equilibrium price $p^{*}=6.039$, polluter $p 1$ supplies a positive amount of abatement credits $\left(q_{p 1}^{*}=2.048\right)$, while polluter $p 2$ demands the sum of these credits and the sequestration produced by the dominant firm and competitive fringe, i.e., $\bar{q}_{p 2}-q / \rho_{2}=8.503 \Rightarrow q_{p 2}^{*}=-8.503$.

As expected, in relation to the competitive benchmark the competitive fringe's equilibrium quantity of sequestration, as well as both polluters' abatement efforts, all decrease in response to the presence of a dominant firm. The equilibrium carbon price also decreases, due to the combination of the dominant firm's lower costs of sequestration and the restriction of the market demand curve (see Figure 2). The decrease

\footnotetext{
${ }^{23}$ The conception of perfect competition in the competitive fringe model is markedly different than in a monopoly model. In a monopoly model, the monopolist's marginal cost curve corresponds to (or is subsumed by) the industry's marginal cost under perfect competition. To the contrary, in a competitive fringe model the fringe's marginal cost curve (which is more steeply sloped than that of the dominant firm) becomes the sole cost curve in the market (and the market demand curve is no longer kinked). Figure 1 illustrates this difference most clearly. In the monopoly model, perfect competition is identified by the intersection of the $M C^{d}$ and (lighter-shaded portion of the) $D$ curves. In the competitive fringe model, the perfect-competition equilibrium occurs where the $M C^{f}$ and $D$ curves intersect. The equilibrium carbon price in the competitive fringe model is therefore higher than in the traditional perfect competition model.
} 
in the (endogenized) licensing fee for the competitive fringe, $F_{f}^{*}$, implies that in equilibrium the size of the fringe's aggregate sequestration decreases in the presence of a dominant firm.

Figures 3 and 4 demonstrate how the initial equilibrium in the competitive fringe model changes for what we label as Case 1; changes that compel the competitive fringe to become progressively more high-cost relative to the dominant firm and the polluters.

\section{[INSERT FIGURES 3 AND 4 HERE]}

In Figure 3, the competitive fringe reduces its aggregate (equilibrium) sequestration in response to the rise in production cost, in this case asymptotically to zero by the $10^{\text {th }}$ step. Both the dominant firm and polluter $p 1$ steadily increase their respective sequestration levels, with polluter $p 1$ increasing its quantity supplied above the dominant firm's by the sixth step. The competitive fringe's equilibrium sequestration level falls at an increasing rate up to the sixth-step. Polluter $\mathrm{p} 2$ 's net demand for sequestration also falls steadily, but at a slower rate than the dominant firm's and polluter p1's sequestration increases.

Concomitant with these quantity changes, Figure 4 shows that the dominant firm's profit increases at a decreasing rate with each step. The carbon price rises along with the dominant firm's profit (and the gradual disappearance of the competitive fringe). This increase is driven by the fact that as the competitive fringe's production cost rises, the dominant firm's residual demand curve effectively shifts outward (in both regions $p_{f}$-to$p_{1}$ and $p_{1}$-to- $p_{2}$ in Figure 2).

The policy implications of these results are twofold. First, if the competitive fringe experiences declines in cost efficiency, say as a result of an increase in the opportunity 
cost of land, the dominant firm's market share vis-à-vis the fringe is, as expected, likely to grow. Second, depending upon the polluting firms' relative abatement efficiencies, it could be that lower-cost polluters gain market share as well. ${ }^{24}$

Figures 5 and 6 demonstrate how the initial equilibrium in the competitive fringe model changes for what we label as Case 2 . These changes reflect a situation in which the dominant firm becomes progressively more low-cost relative to the competitive fringe and the polluters.

\section{[INSERT FIGURES 5 AND 6 HERE]}

In Figure 5 we see that, unlike in Figure 3, these changes result in both the competitive fringe and low-cost polluter $p 1$ losing market share to the dominant firmthe dominant firm and competitive fringe are sole suppliers of sequestration by the $10^{\text {th }}$ step. Figure 6 shows that the carbon price falls as the dominant firm's market share increases. This is a standard result, since the only change that has occurred in this case is a fall in the dominant firm's marginal sequestration cost. The residual demand curve has not shifted.

In sum then, the way in which a wedge is driven between the cost efficiencies of the dominant firm and competitive fringe has important implications for the equilibrium allocation of sequestration and the corresponding carbon price. The same wedge can be associated with low-cost polluters gaining or losing market share and the carbon price rising or falling.

\footnotetext{
24 "Market share" in this sense means proportion of aggregate sequestration/abatement supplied by either the dominant firm, competitive fringe, or the high- and low-cost polluter, whichever is in question.
} 
Lastly, Figures 7 and 8 demonstrate how the initial equilibrium in the competitive fringe model changes for a third case. These changes reflect stricter regulatory standards enacted for both polluting firms.

\section{[INSERT FIGURES 7 AND 8 HERE]}

In Figure 7 we see that sequestration outputs rise for the dominant firm, competitive fringe, and low-cost polluter, but any changes in market share between these agents is miniscule. The high-cost polluter responds by producing less abatement, and therefore demanding more sequestration. Figure 8 shows that these quantity changes are associated with a steady rise in the carbon price, the aggregate output of the competitive fringe, and dominant firm profit (although the rise in profit is much less pronounced in this case). Hence, any windfall from the change in regulatory standards is shared roughly equally by the dominant firm, competitive fringe, and low-cost polluter.

\section{Summary and Discussion}

This paper makes two contributions to the carbon-sequestration literature; a literature which has heretofore been focused on the empirical estimation of sequestration supply functions, both for specific countries and globally. The first contribution is to develop a theoretical framework within which the comparative statics of sequestration and permit trading may be jointly analyzed in the context of a competitive fringe model. An empirically based motivation for developing this framework is provided by Benitez, et al. (2007), who find that low-cost sequestration sites are mainly located in regions such as Sub-Saharan Africa, southeastern Brazil, and Southeast Asia. This suggests that the equilibrium emerging in a regional or global sequestration market may be governed more 
by the interplay of a dominant firm (e.g., public land owned by a specific region or nation) and a competitive fringe (e.g., private land owned by U.S. farmers) than by perfect competition within a given nation (as assumed by Stavins,1999, and Lubowski, et al., 2006).

The second contribution is to numerically analyze the competitive fringe/permittrading model. We have considered three cases. In the first two cases we assess the responsiveness of sequestration to changes in the relative cost structures of the dominant firm and competitive fringe. In Case 1, the equilibrium allocation of sequestration aligns with a higher carbon price in response to an increase in the competitive fringe's marginal cost parameter. Conversely, in Case 2 the carbon price falls when the dominant firm experiences a decrease in its marginal cost parameter. Taken together, these results imply that how cost efficiencies change between the dominant firm and competitive fringe matters when it comes to predicting the corresponding direction of the equilibrium carbon price and changes in relative market shares (including the shares of the polluters themselves).

In Case 3 we evaluate the impact of stricter regulation on the abatement decisions of the polluting firms. We find that respective increases in the polluting firms' required abatement levels induce higher sequestration levels from both the dominant firm and competitive fringe, as well as from the low-cost polluter. The equilibrium carbon price rises as well.

Of course numerical analysis based on ad hoc parameter values and functional forms is limited by its inability to inform policy with anything other than a more qualitative assessment of equilibrium allocations in a relative sense, e.g., by answering questions 
such as how 'smooth' might be the disappearance of a competitive fringe as the dominant firm becomes more cost-effective in its production of sequestration, or vice-versa? Until the parameter values and functional forms themselves are empirically estimated and incorporated into the numerical analysis, the numerical model will be limited in its policy relevance.

The current numerical analysis nevertheless offers some important caveats for policymakers. For example, the results for Cases 1 and 2 demonstrate that as the dominant firm becomes more cost-effective at producing sequestration relative to the competitive fringe the attendant effects on low-cost polluters and the carbon price are ambiguous - low-cost polluters may gain or lose market share in abatement and the equilibrium carbon price may rise or fall. In particular, if the cost-efficiency wedge between the competitive fringe and the dominant firm widens as a result of the competitive fringe experiencing a ceteris paribus rise in production costs (i.e., a reduction in cost effectiveness relative to the dominant firm), then the low-cost polluters gain market share and the equilibrium carbon price increases. To the contrary, if the wedge widens as a result of the dominant firm experiencing a ceteris paribus fall in production costs (i.e., an increase in cost effectiveness relative to the competitive fringe), the lowcost polluters lose market share and the equilibrium carbon price decreases. To the extent that we care about these types of market share and pricing issues we therefore need to care about how the cost-efficiency wedge develops between the dominant firm and competitive fringe. Or, alternatively stated, we need to understand the equilibrium effects associated with policies that might create such a wedge. 
Similarly, Case 3 demonstrates the effects of changes in regulatory standards on the polluters' relative market shares and the equilibrium carbon price. To the extent that we care about these effects we therefore must concern ourselves with the way in which regulatory standards are adjusted. This paper's numerical results suggest that uniform changes in standards, e.g., a uniform increase in required abatement across polluters in a permit market, may have starkly different effects on high- and low-cost polluters, but not as pronounced effects on their respective market shares as policies affecting the relative sequestration productivities of the dominant firm and competitive fringe.

Of course, criticism against the ad hoc nature of numerical analysis can also be levied against what is effectively ad hoc empirical analysis. Until empirical analyses such as Stavins' (1999), Lubowski, et al.'s (2006), and Benitez, et al.'s (2007) account for both the global nature of the carbon sequestration problem and the corresponding market structures that are most likely to govern the behavior of the various agents involved, estimates of what are inherently endogenous variables (e.g., the allocation of sequestration and abatement across these agents and the resulting equilibrium carbon price) will be biased estimates of the equilibrium outcomes themselves.

Thus, the avenue for future research seems clear. Demand-side information should be incorporated into supply-side models. This information should be global in scale (or regional if carbon emissions are to be controlled via a set of region-based agreements a la Asheim, et al., 2006) and reflective of the prevailing market structure. Incorporation of this type of information into national supply-side models, such as those of Lubowski, et al. (2006) and Stavins (1999), will enhance the accuracy and reliability of supply estimates by reflecting what is a likely in the wider realm of a global equilibrium, rather 
than what is possible under the parochial assumptions of perfect competition. The same can be said for global supply-side models, such as Benitez, et al.'s (2007).

With respect to the role that market structure might play in the allocation of sequestration and abatement on a global or regional scale, echoes can be heard of Hahn's (1984) seminal article demonstrating the importance of market power in determining an equilibrium outcome. Without accounting for market structure, empirical predictions of equilibrium outcomes in sequestration and abatement markets are likely to be biased. 


\section{References}

Asheim, G.B., C.B. Froyn, J. Hovi, F.C. Menz (2006). Regional versus global cooperation for climate control. Journal of Environmental Economics and Management 51(1), 93-109.

Benitez, P.C., I. McCallum, M. Obersteiner, and Y. Yamagata (2007). Global potential for carbon sequestration: Geographical distribution, country risk and policy implications. Ecological Economics 60, 572-583.

Carlton, D.W. and J.M. Perloff (2004). Modern industrial organization, fourth edition. New York: Pearson Addison Wesley.

de Jong, B.H., R. Tipper, and G. Montoya-Gomez (2000). An economic analysis of the potential for carbon sequestration by forests: evidence from southern Mexico. Ecological Economics 33, 313-327.

Fearnside, P.M. (1995). Global warming response in Brazil's forest sector: Comparison of project-level costs and benefits. Biomass and Bioenergy 8, 309-322.

Godby, R. (2000). Market power and emissions trading: Theory and laboratory results. Pacific Economic Review 5(3), 349-363.

Hahn, R.W. (1984). Market power and transferable property rights. The Quarterly Journal of Economics 99(4), 753-765.

Jindal, R., B. Swallow, and J. Kerr (2008). Forestry-based carbon sequestration projects in Africa: Potential benefits and challenges. Natural Resources Forum 32, 116-130.

Jindal, R., J. Kerr, and S. Nagar (2011). Voluntary carbon trading: Potential for community forestry projects in India. Unpublished manuscript, Michigan State University. Retrieved from the internet on July 18, 2011 at http://static.globaltrade.net/files/pdf/20100215233224.pdf.

Kolstad, C.D. (2011). Environmental economics, second edition. New York and Oxford: Oxford University Press.

Lal, R. (2004). Soil carbon sequestration impacts on global climate change and food security. Science 304(5677), 1623-1627.

Liski, M. and J-P Montero (2006). On pollution permit banking and market power. Journal of Regulatory Economics 29(3), 283-302.

Lubowski, R.N., A.J. Plantinga, and R.N. Stavins (2006). Land-use change and carbon sinks: Econometric estimation of the carbon sequestration supply function. Journal of Environmental Economics and Management 51, 135-152. 
Muller, R.A., S. Mestelman, J. Spraggon, and R. Godby (2002). Can auctions control market power in emissions trading markets? Journal of Environmental Economics and Management 44(1), 70-92.

Ney, R.A., T.A. Meyers, A. Espina, J.L. Schnoor (2005). How many samples are required? Evaluating a model for verification of carbon sequestration in a hybrid poplar buffer strip. Environmental Monitoring and Assessment 102 (1-3), 375-388.

Ravindranath, N.H. and B.S. Somashekhar (1995). Potential and economics of forestry options for carbon sequestration in India. Biomass and Bioenergy 8, 323-336.

Sedjo, R. (1999). Potential for carbon forest plantations in marginal timber forests: The case of Patagonia, Argentina. Discussion Paper 99-27. Resources for the Future, Washington DC.

Sohngen, B. and R. Sedjo (2004). Carbon sequestration in global forests. Resources for the Future, Washington, DC.

Stavins, R.N. (1999). The costs of carbon sequestration: A revealed-preference approach. American Economic Review 89(4), 994-1009.

Subak, S. (2002). Forest certification eligibility as a screen for CDM sinks projects. Climate Policy 2(4), 335-351.

Tietenberg, T. (2006). Environmental and natural resource economics, seventh edition. Boston: Pearson Education, Inc.

UNFAO (2004). A review of carbon sequestration projects. AGL/MISC/37/2004. Land and Plant Nutrition Service, Land and Water Development Division, Food and Agriculture Organization of the United Nations, Rome, Italy.

UNFCC (1998). Report of the conference of the parties on its third session, held in Kyoto from December 1 to 11, 1997. FCCC/CP/1997/7/Add.1. United Nations Framework Convention on Climate Change (UNFCCC), Bonn, Germany.

U.S. Department of Energy (U.S. DOE) (2009). Geologic sequestration research. Fossil Energy Office of Communications. Retrieved from the internet on February 17, 2010 at http://www.fossil.energy.gov/programs/sequestration/geologic/.

$\mathrm{Xu}, \mathrm{D}$. (1995). The potential for reducing atmospheric carbon by large-scale afforestation in China and related cost/benefit analysis. Biomass and Bioenergy8, 337-344. 
Figure 1. Standard Competitive Fringe Model.

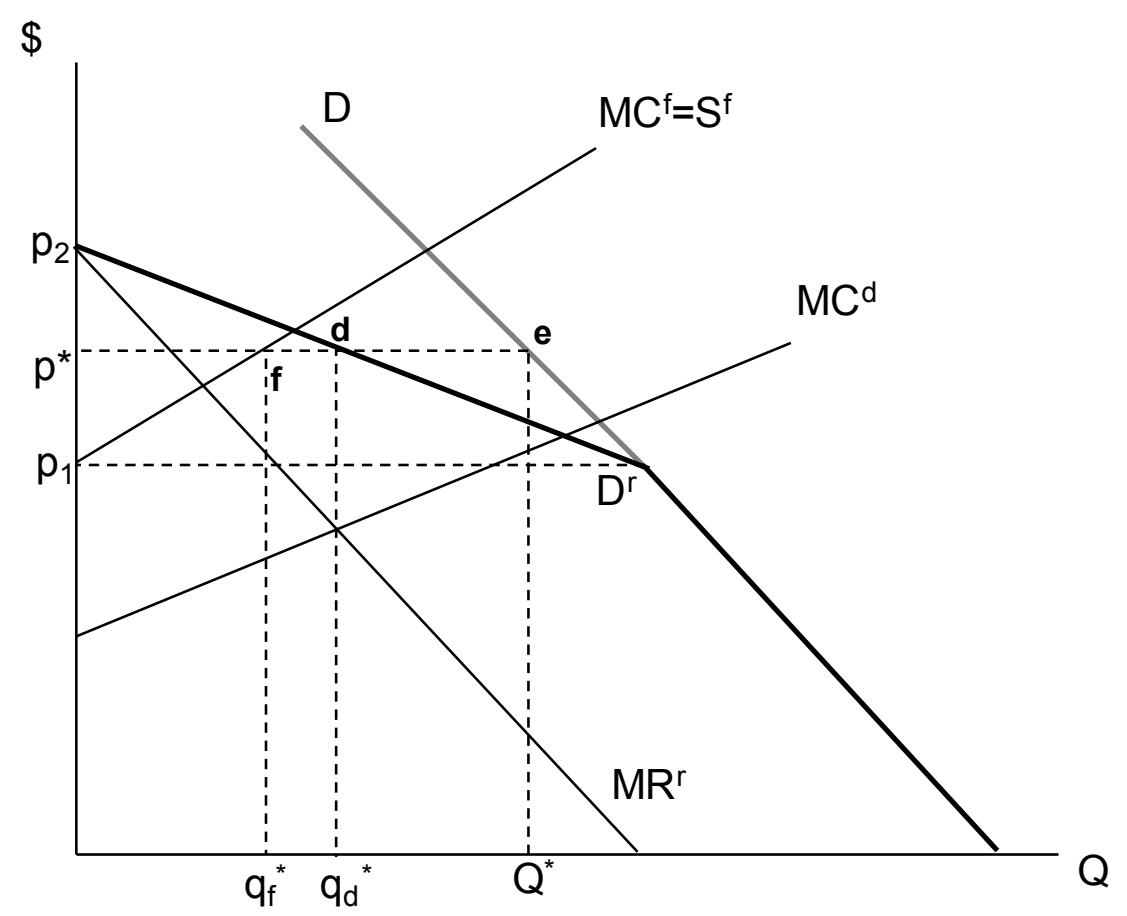


Figure 2. Competitive Fringe Model with Permit Trading.

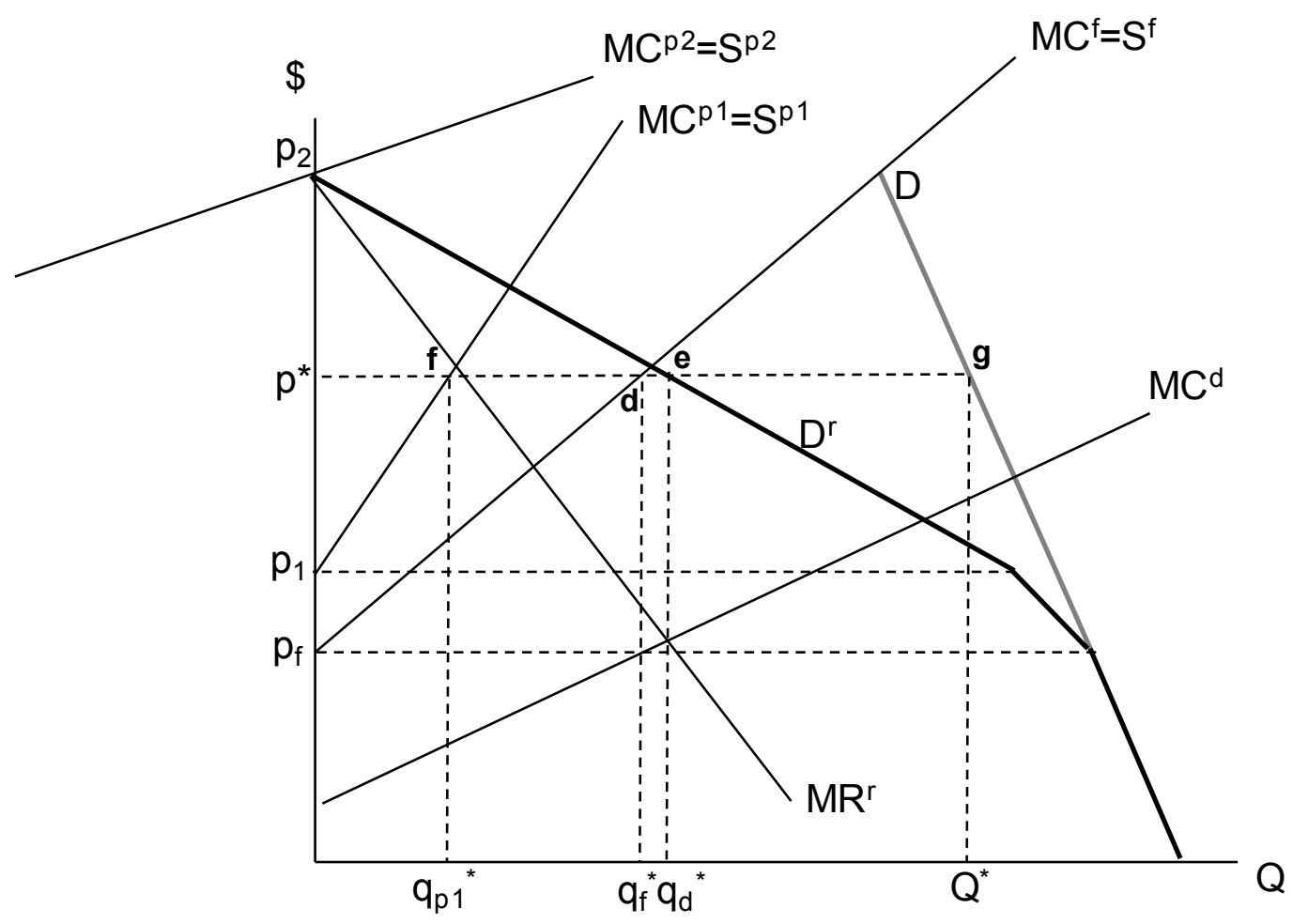


Figure 3. Sequestration Quantities for Case 1.

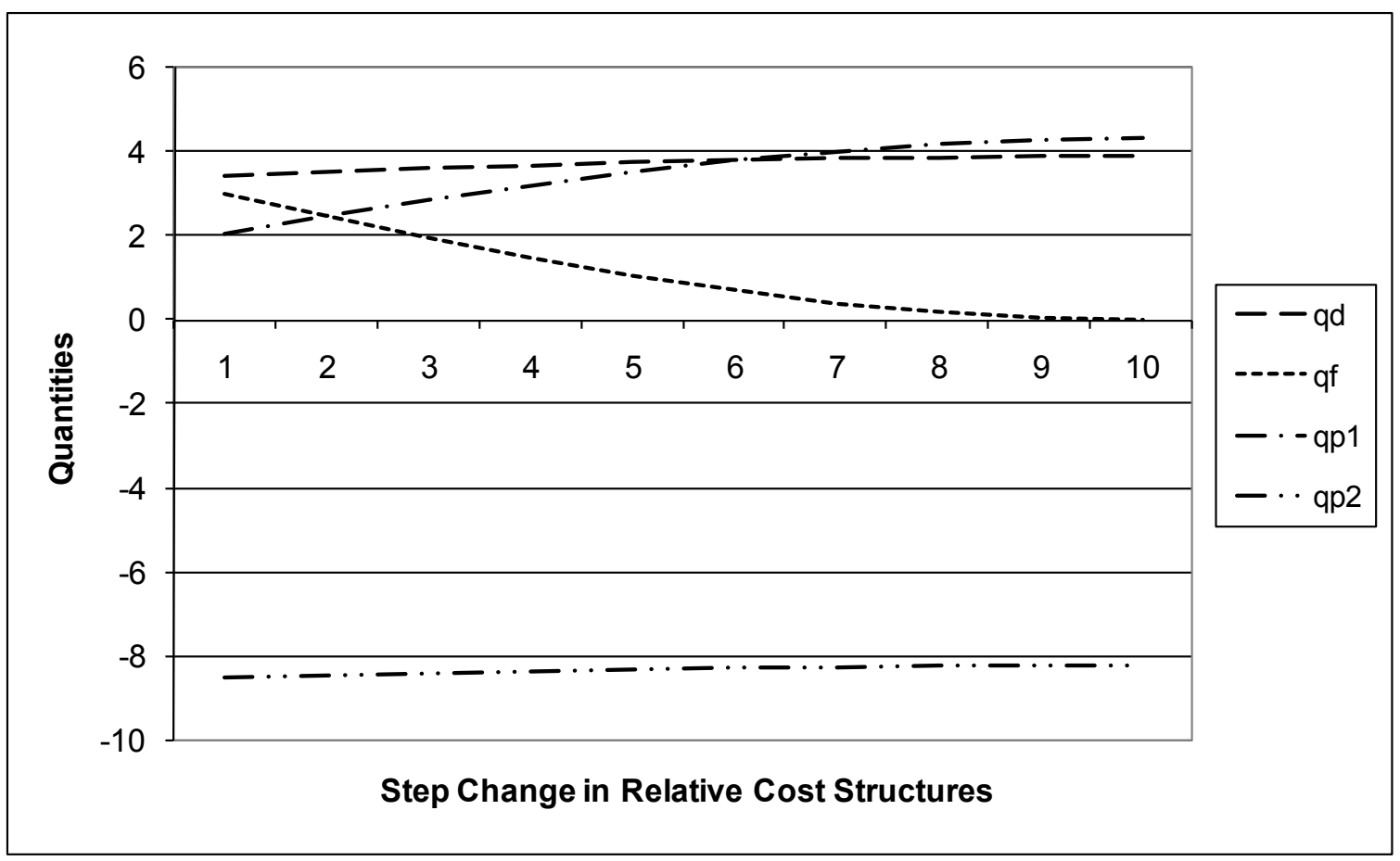

Figure 4. Carbon Price, Dominant Firm Profit, and Fringe License Fees For Case 1.

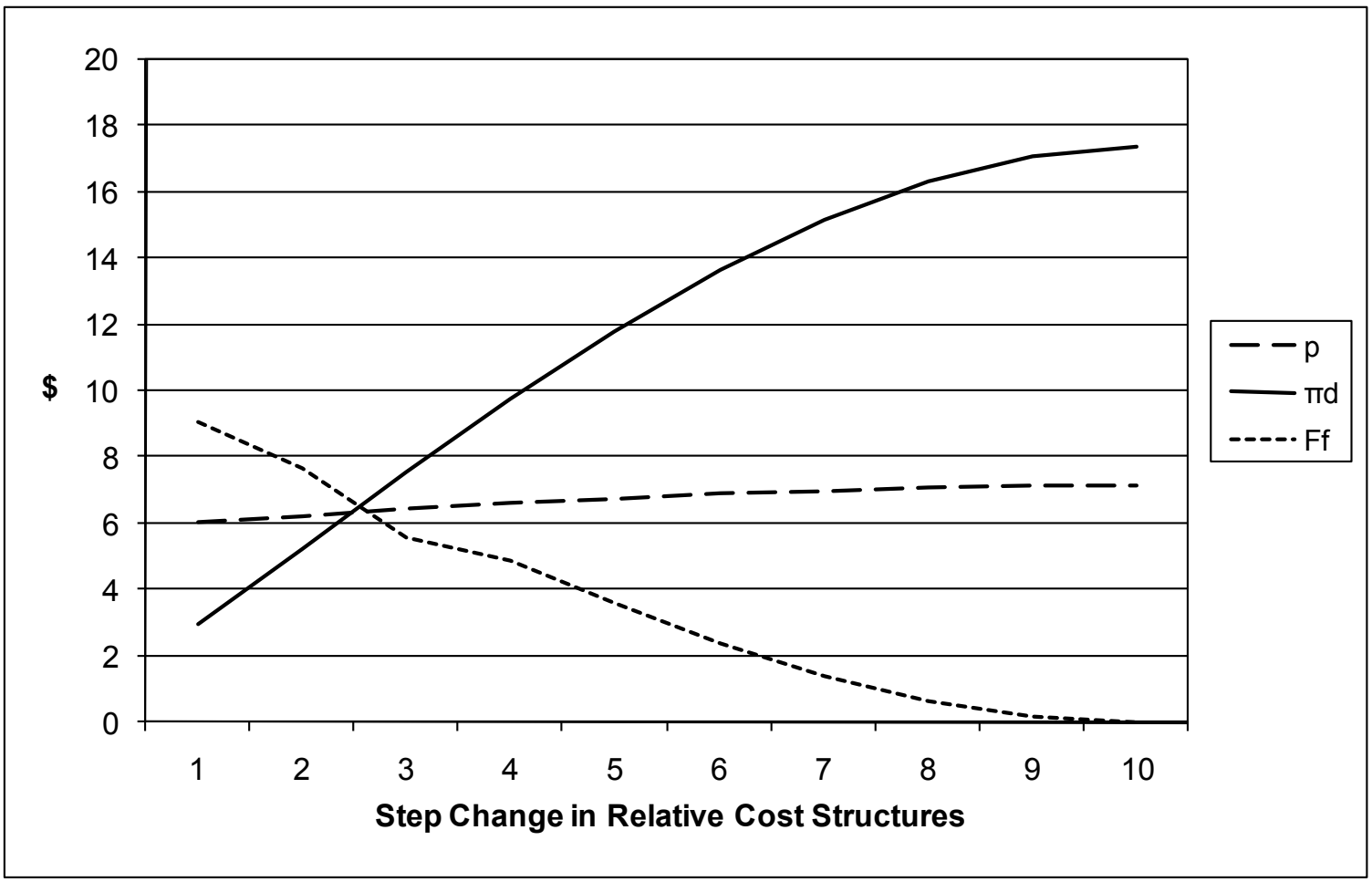


Figure 5. Sequestration Quantities for Case 2.

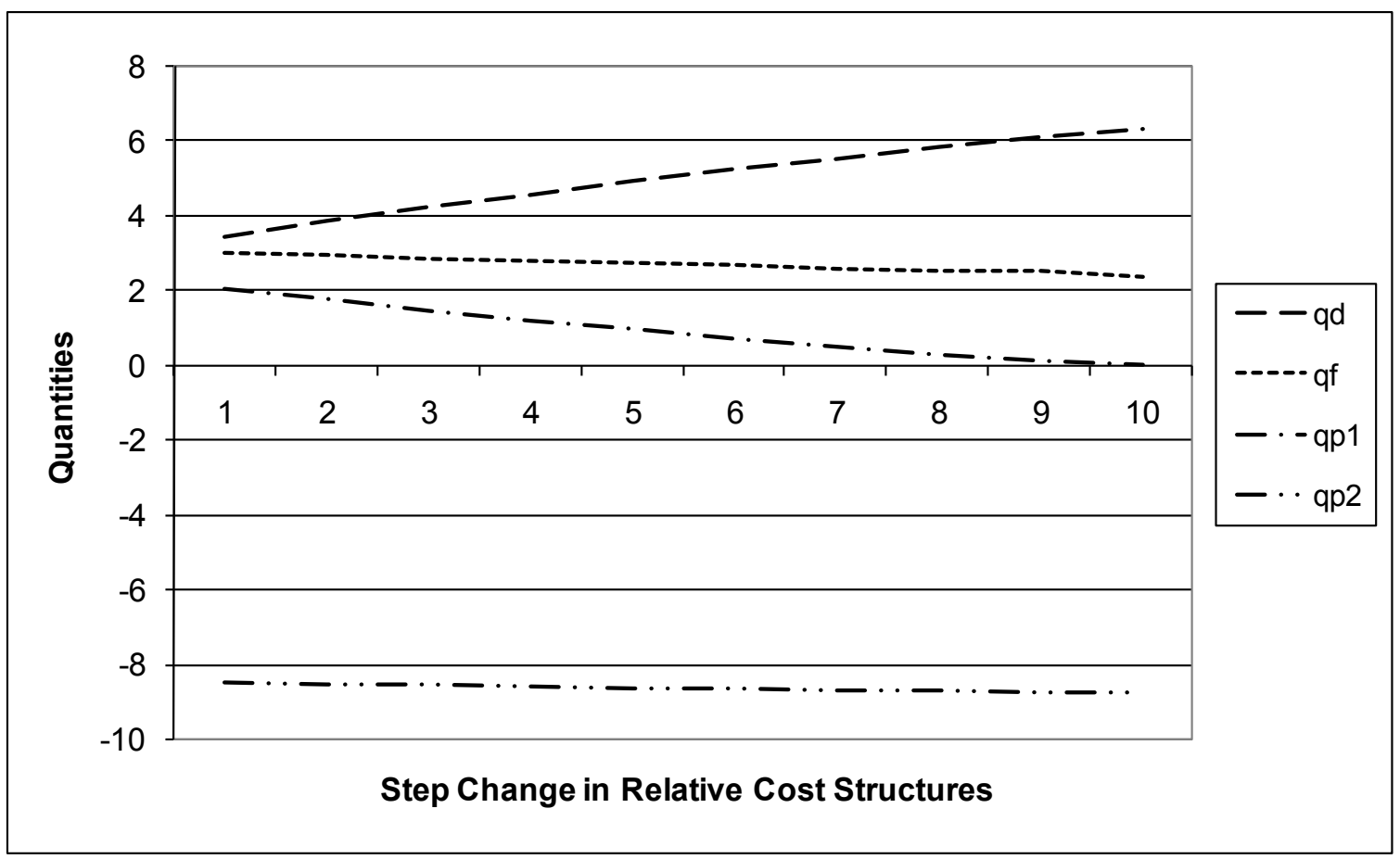

Figure 6. Carbon Price, Dominant Firm Profit, and Fringe License Fees For Case 2.

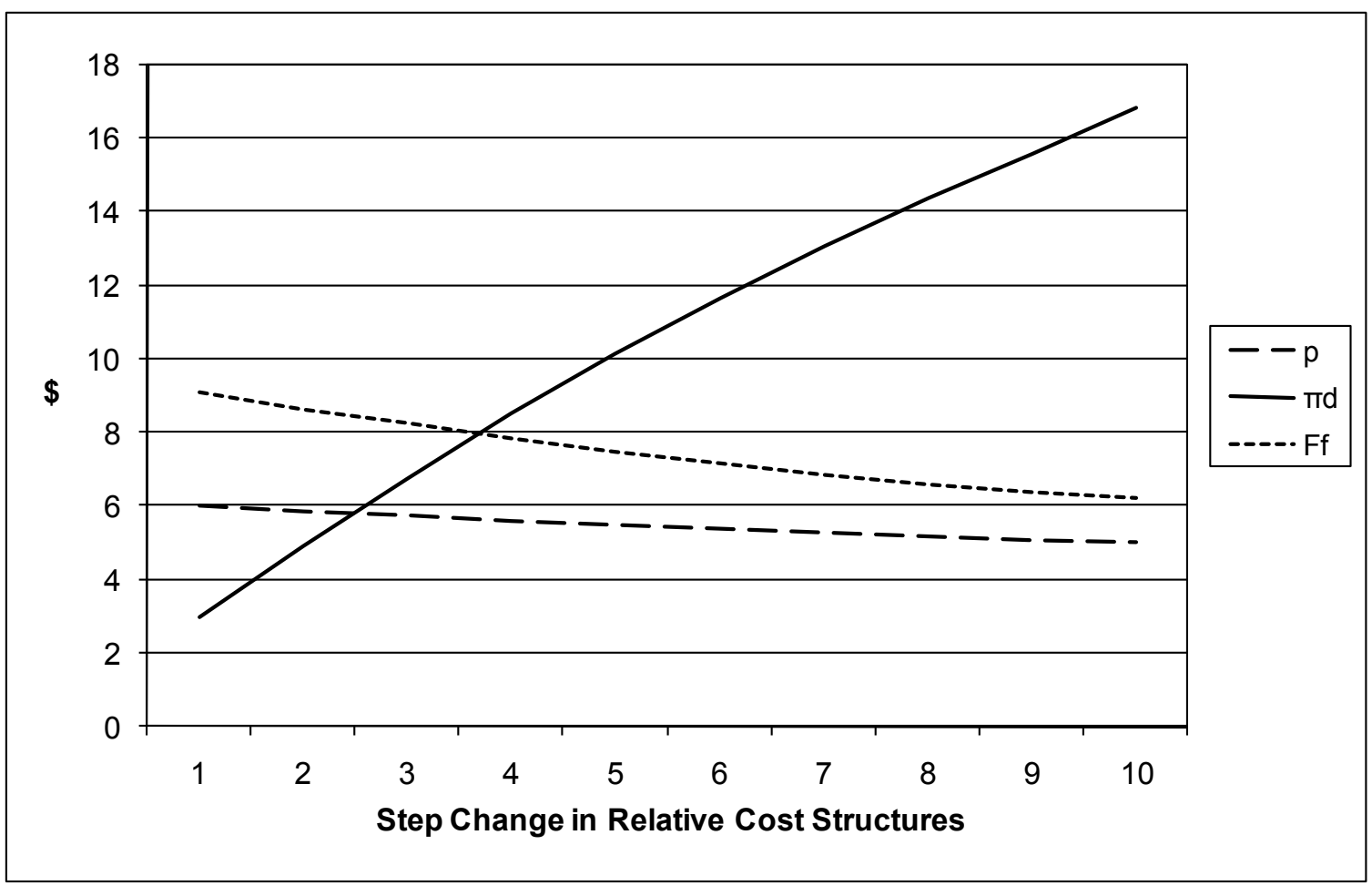


Figure 7. Sequestration Quantities for Case 3.

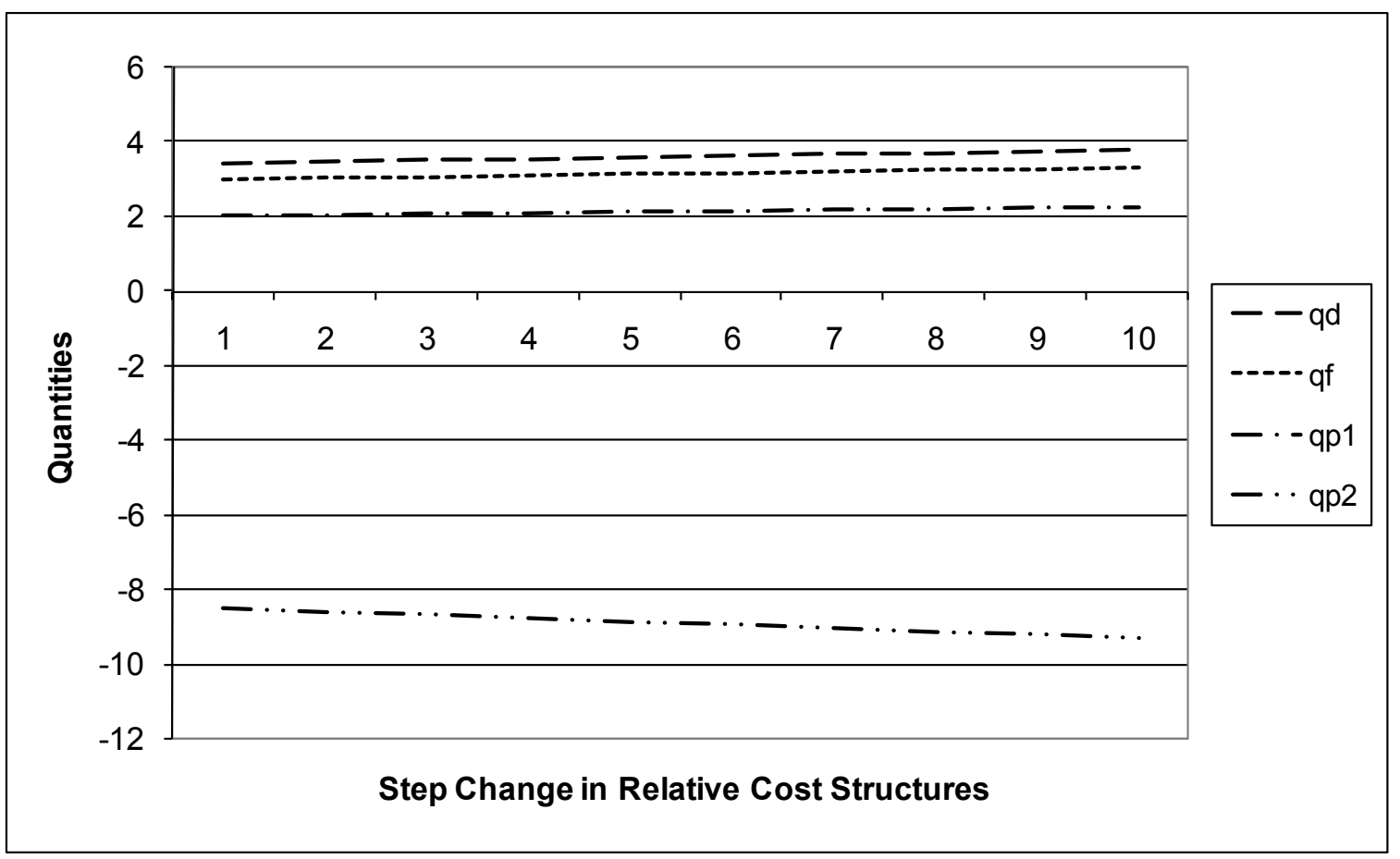

Figure 8. Carbon Price, Dominant Firm Profit, and Fringe License Fees For Case 3.

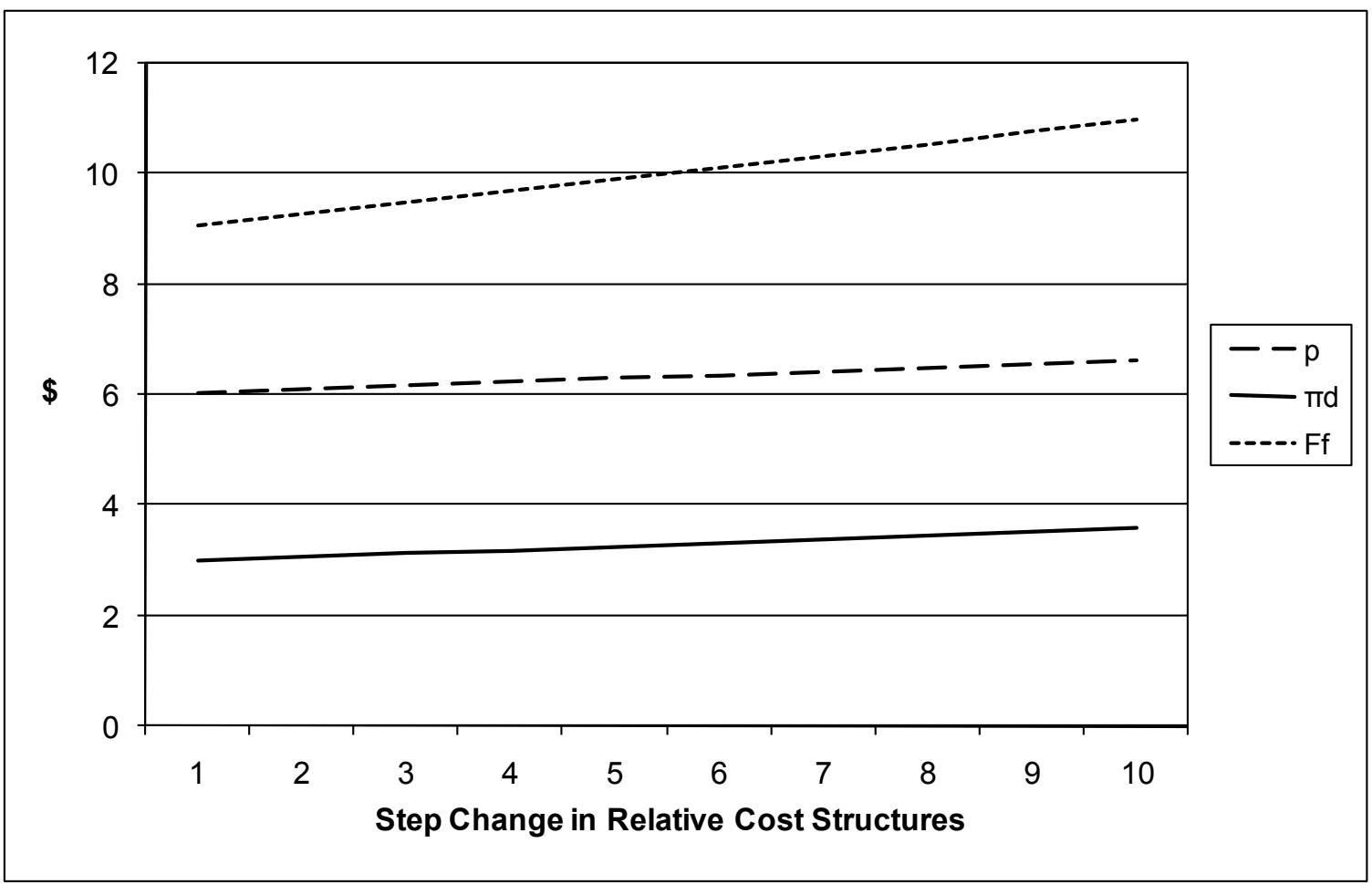


Table 1. Initial Parameter Values for Numerical Analysis.

\begin{tabular}{cc} 
Parameter & Initial Value \\
\cline { 2 - 2 }$\alpha_{d}$ & 0.009 \\
$\alpha_{f}$ & 0.01 \\
$\alpha_{p 1}$ & 0.015 \\
$\alpha_{p 2}$ & 0.05 \\
$\beta_{p 1}$ & 0.25 \\
$\beta_{p 2}$ & 2.0 \\
$\varepsilon_{d}$ & 1.2 \\
$\varepsilon_{f}$ & 1 \\
$v$ & 1.05 \\
$\bar{q}_{p 1}$ & 10 \\
$\bar{q}_{p 2}$ & 10
\end{tabular}


Table 2. Equilibrium Solutions Based on Initial Parameter Values.

\begin{tabular}{|c|c|c|}
\hline Variable & $\underline{\text { Perfect Competition }}$ & Competitive Fringe \\
\hline$q_{d}^{*}$ & --- & 3.441 \\
\hline$q_{f}^{*}$ & 3.640 & 3.014 \\
\hline$q_{p 1}^{*}$ & 4.550 & 2.048 \\
\hline$q_{p 2}^{*}$ & -8.190 & -8.503 \\
\hline$p^{*}$ & 7.290 & 6.039 \\
\hline$\pi_{d}^{*}$ & --- & 2.985 \\
\hline$F_{s}^{*}$ & 13.250 & 9.087 \\
\hline
\end{tabular}

